\title{
The stratopause evolution during different types of sudden stratospheric warming event
}

\author{
Etienne Vignon • Daniel M. Mitchell
}

Received: 18 February 2014 / Accepted: 5 August 2014 / Published online: 26 August 2014

(C) The Author(s) 2014. This article is published with open access at Springerlink.com

\begin{abstract}
Recent work has shown that the vertical structure of the Arctic polar vortex during different types of sudden stratospheric warming (SSW) events can be very distinctive. Specifically, SSWs can be classified into polar vortex displacement events or polar vortex splitting events. This paper aims to study the Arctic stratosphere during such events, with a focus on the stratopause using the Modern Era-Restrospective analysis for Research and Applications reanalysis data set. The reanalysis dataset is compared against two independent satellite reconstructions for validation purposes. During vortex displacement events, the stratopause temperature and pressure exhibit a wave- 1 structure and are in quadrature whereas during vortex splitting events they exhibit a wave- 2 structure. For both types of SSW the temperature anomalies at the stratopause are shown to be generated by ageostrophic vertical motions. Transformed Eulerian mean diagnostics are used to show differences in the planetary wave activity between displacement and splitting events. The convergence of Eliassen-Palm flux, which leads to SSWs is longer for displacement events and a persistent mesospheric Eliassen-Palm flux divergence can be observed about 20 days after displacement events. Finally, although this work focuses on the stratopause at high latitudes, associated observations of the equatorial middle atmosphere are also examined to explore links between the equator and polar evolution during SSWs.
\end{abstract}

\section{E. Vignon}

Département des Géosciences,

Ecole Normale Supérieure, Paris, France

e-mail: etienne.vignon@ens.fr

\section{M. Mitchell ( $₫)$}

Atmospheric, Oceanic and Planetary Physics,

Department of Physics, University of Oxford, Oxford, UK

e-mail: d.mitchell1@physics.ox.ac.uk
Keywords Stratopause $\cdot$ Sudden stratospheric warming MERRA data $\cdot$ Polar vortex ·

Middle atmospheric circulation

\section{Introduction}

The stratopause is characterised by a reversal of the atmospheric lapse rate at around $50 \mathrm{~km}(\sim 1 \mathrm{hPa})$. While stratospheric ozone heating is responsible for the stratopause presence at sunlit latitudes, westward gravity wave drag (and to a lesser extent, stationary gravity wave drag) maintains the stratopause in the polar night jet (Hitchman et al. 1989). Indeed, the westward and stationary gravity wave (GW) breaking induces a mesospheric meridional flow toward the winter pole with a confined descending branch over the vortex. It leads to a warming around $60 \mathrm{~km}$ and so to a separation between the polar stratopause and the lower latitude stratopause, with the climatological zonally-averaged summer hemisphere and lower latitude stratopause generally positioned at a lower altitude than the winter stratopause.

France et al. (2012) performed a month-by-month climatology of the stratopause in the two hemispheres using seven years of Microwave limb sounder (MLS) satellite data. Their study particularly focused on the link between the stratopause, the polar vortex and the middle atmosphere winter anticyclones. They show that in October, as the polar sun heating has decreased, the northern polar stratopause inside the vortex is not due to ozone heating anymore but is maintained by westward GW driven descents at higher altitude. While the stratopause height maximum is located over the vortex, the stratopause temperature minimum is located over Canada, at the vortex edge. In November, the vortex becomes stronger and allows a higher critical level for westward GWs and thus a higher stratopause. 
From December to February, the planetary wave (hereafter PW) activity is enhanced. As it propagates upward more easily, a wave-1 PW dominates the stratopause temperature pattern (wave 2 PWs are mainly filtered in the troposphere and in the stratosphere) and a baroclinic structure develops in the middle atmosphere (Simmons 1974; Fairlie et al. 1990; Thayer et al. 2010). The stratopause height is therefore maximum inside the vortex, it is minimum inside the anticyclone and is in quadrature with the stratopause temperature during the PW activity peak. France and Harvey (2013) attribute the climatological warm/cold stratopause temperature anomalies to local ageostrophic descent/ascent associated with the baroclinic structure due to the PW propagation and breaking. On average, the stratopause is $20 \mathrm{~K}$ colder and 5-10 km lower within the Aleutian anticyclone than in ambient air and the coldest temperatures are observed on the west edge of the vortex, consistent with the satellite observations (Labitzke 1974). In March, the vortex and anticyclone weaken, the baroclinic structure decays, the sunlight and ozone heating start to heat the mid-latitude stratopause and the stratopause temperature and height become inversely correlated.

Furthermore, the northern winter stratosphere is often affected by extreme events called sudden stratospheric warmings. These events follow strong PW activity in the middle atmosphere and are characterized by a rapid warming of the polar stratosphere, a strong weakening of the vortex, and a modification of its shape (Waugh and Randel 1999; Mitchell et al. 2011). These events can be classified into two groups: displacement events, when the polar vortex is displaced off the pole, and splitting events, when the vortex is divided into two smaller ones (Andrews et al. 1987). Recent work has emphasised the importance of looking at the surface climate before (Cohen and Jones 2012) and after (Mitchell et al. 2013) such events.

During NH winters which are affected by sudden stratospheric warmings [hereafter sudden stratospheric warming (SSW)], stratopause features dramatically differ from the undisturbed climatology. From rocket data, Labitzke (1981) showed a stratopause descent and warming during the SSW onset and its destruction at the warming peak when the low mesosphere-upper stratosphere is nearly isothermal. This stratopause warming can be dramatic and its temperature can often reach values higher than $300 \mathrm{~K}$ (Braesicke and Langematz 2000). Moreover, Siskind et al. (2007) used Sounding of the Atmosphere with Broadband Emission Radiometry data to explore the intrusion of NOx and $\mathrm{CO}$ from the high mesosphere into the stratosphere during the particularly strong 2005-2006 SSW. They point out an unusual vertical displacement of the polar stratopause to $80 \mathrm{~km}$ after the warming. High altitude PW activity during the warming and its poleward and downward air motion are considered to be responsible for the NOx intrusion into the stratosphere [see also Holt et al. (2013)]. Manney et al. (2008) provide a detailed description of the particular 2006 sudden warming. When the polar vortex starts to recover in the upper stratosphere about 10 days after the SSW peak, a cool stratopause reforms above 75 $\mathrm{km}$, remains elevated for about 20 days and then drops to its climatological altitude. These extreme events are called 'elevated stratopause events' (hereafter ES events) and occur between 2 and 4 times each decade (France and Harvey 2013). The reformation of the stratopause is attributed to mesospheric PW activity after a SSW (Limpasuvan et al. 2012) and to non-orographic GW drag in the mesosphere (Ren et al. 2011; Chandran et al. 2011; Tomikawa et al. 2012; Yamashita et al. 2013; Zülicke and Becker 2013).

The focus of studies regarding the northern polar stratopause structure have principally been studied during specific ES events, but, to our knowledge, no study have identified common characteristics of the stratopause during all the SSW events, whether or not they are followed by an ES event. Moreover, most of the studies on the stratopause have focused on the last decade because of the lack of satellite data before then. In order to understand the occurrence of the ES events in the last decades and their formation after certain SSW events, a first approach could consist of exploring common features of the stratopause during SSW events a in a large dataset like a meteorological reanalysis. Chandran et al. (2013) examined the influence of the type (displacement/splitting) of SSW on the formation of an ES and found that $68 \%$ of the ES events followed a splitting event in a 52 years simulation in the World Atmosphere Community Climate Model. It is therefore interesting to compare and contrast the stratopause behaviour during the two types of SSW in order to better understand the mecanism of ES events, especially using reanalysis data which resolve the upper stratosphere and lower mesosphere. In the same way, it is useful to see if the stratopause structure is a good indicator of the middle-atmospheric circulation during the two types of SSW events, especially as many SSW events start at high altitudes and descend through the stratosphere.

The paper is structured as follow. First of all, the data and analysis techniques used in this work are described in Sect. 2. Section 3 presents our results on the stratopause climatology and on the stratopause behaviour during SSWs in the Modern Era-Restrospective analysis for Research and Application (MERRA) data. A general conclusion in Sect. 4 closes the article. 


\section{Data and analysis techniques}

\subsection{The MERRA dataset}

In this study, the MERRA reanalysis dataset was chosen because it extends to $0.02 \mathrm{hPa}$, this includes the stratosphere and much of the mesosphere. The MERRA reanalysis uses the Goddard Earth Observing System Data Assimilation System Version 5 (GEOS-5) model (Rienecker et al. 2011). GEOS-5 uses two GW parametrizations: drag from orographic GWs based on McFarlane (1980), and drag from non-orographic GWs based on Garcia and Boville (1994). In this study we make use of the daily-mean and monthly-mean data from the 1st January 1979 to the 31 st December 2012. All data are available on 42 standard pressure levels (from 1000 to $0.1 \mathrm{hPa}$ ). The horizontal resolution of the model is $1.25^{\circ}$ latitude by $1.25^{\circ}$ longitude. However, additional models levels were also used to extend the analysis to $0.02 \mathrm{hPa}$. The consistency of the additional levels with the interpolated levels of the final MERRA product has been found to be good by comparing time series and the climatologies of overlapping levels around $0.1 \mathrm{hPa}$.

The MERRA data represent well the polar stratospheric circulation (Rienecker et al. 2011) and capture most features of the upper stratosphere-lower mesosphere as well as the time evolution of the undisturbed polar stratopause. However, Manney et al. (2008) show that different structures of the upper stratosphere and mesosphere are not well captured in analyses performed using systems that assimilate only nadir-sounding radiance observations (like MERRA reanalyses). They particularly note that models with a lid heights below $0.01 \mathrm{hPa}$ and with a coarse GW scheme may not represent the mesospheric circulation well under extreme events like SSWs. Despite these limits, Manney et al. (2008) conclude that analysis systems using the GEOS-5 model are appropriate to study the PW structure near the stratopause. This is why the main features of the SSWs in the MERRA data shown in this study are believed to be quite well representative of the real circulation.

\subsection{Satellite data}

To validate the MERRA representation of the stratopause, the satellite MLS high-resolution data and the High Resolution Dynamic Limb Sounder (HIRDLS) data have been used. MLS is positioned at a $705 \mathrm{~km}$ sun-synchronous orbit and measures thermal microwave emissions from the Earth's limb up to a latitude of $80^{\circ}$ (Waters 2006). The vertical resolution of the temperature measurements is 5.5 $\mathrm{km}$ at $3 \mathrm{hPa}$ and $8 \mathrm{~km}$ at $0.01 \mathrm{hPa}$ The temperature precision for the v3.3 version (used in this study) is $1 \mathrm{~K}$ with a height-dependant bias between -2.5 and $1 \mathrm{~K}$ (Livesey et al. 2011). HIRDLS has a better vertical resolution than MLS (1 km), a latitude coverage up to a latitude of $80^{\circ}$ and the temperature precision at the stratopause is $1 \mathrm{~K}$ (Gille et al. 2003). The instrument was damaged during the takeoff and has been out of order since March 2008. Nevertheless, Gille et al. (2008) have introduced corrections for the errors introduced by this failure and certain data products, including temperature and pressure, are now available for the period 2005-2008.

\subsection{Analysis method}

In order to identify the stratopause in MERRA, MLS and HIRDLS data, we use the algorithm developed in France and Harvey (2013), detailed as follows:

- The temperature data is interpolated from pressure surfaces to geometric height. ${ }^{1}$

- An $11 \mathrm{~km}$ box car vertical smoothing of the temperature is applied to smooth the local small extrema at each point on the horizontal grid.

- The initial identification locates the temperature maximum in the smoothed profile above $20 \mathrm{~km}$ altitude.

- The accurate position of the stratopause is then determined using the unsmoothed vertical temperature profile to identify the exact temperature maximum $15 \mathrm{~km}$ around the maximum in the smoothed profile.

- A final step consists of checking if the lapse rate is negative above and positive below the later maximum. If yes, the stratopause is defined, if not, the grid point is considered without significant stratopause.

- The onset dates of the SSWs until 2001 used in this study have been identified in Mitchell et al. (2013) and Seviour et al. (2013) using elliptical diagnostics of the potential vorticity fields and of the geopotential fields respectively.

\section{Results}

\subsection{The stratopause climatology}

Figure 1 shows the latitude-time section of the zonal mean stratopause pressure and the zonal mean stratopause temperature over the period of 1979-2012. When compared with the corresponding plots using MLS data in France et al. (2012), the main features of the zonal stratopause are apparent. The warmest stratopause is located where

\footnotetext{
1 The geometric height is the pressure equivalent height for a fixed surface pressure and for a standard temperature profile.
} 

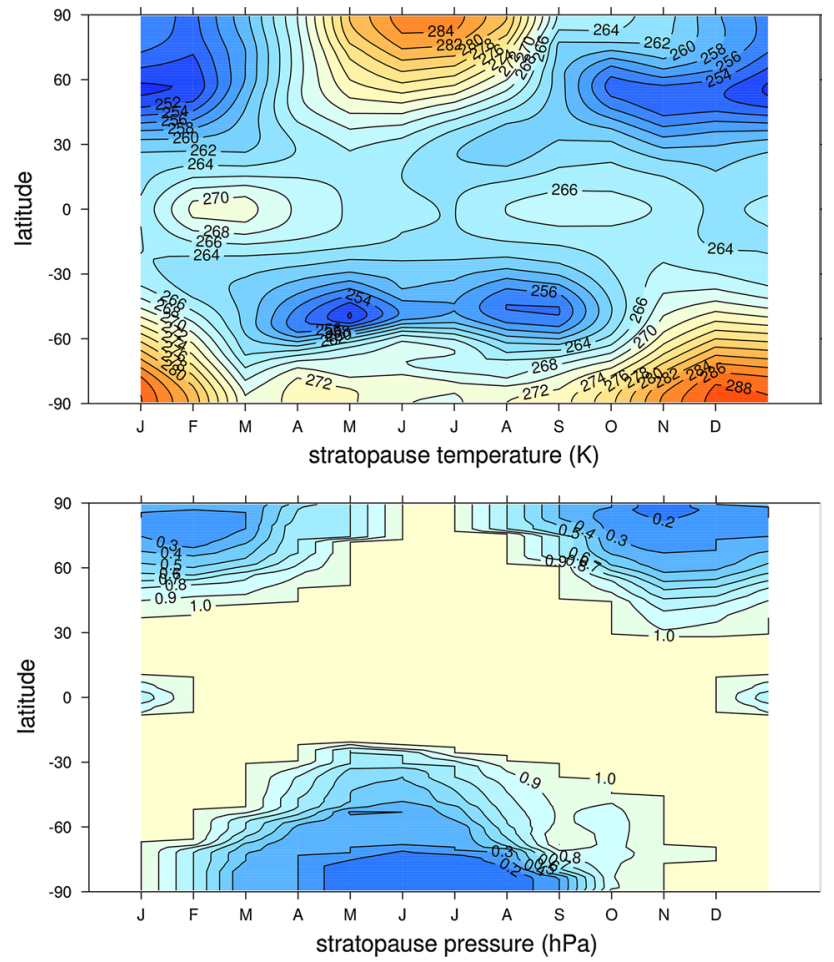

Fig. 1 Latitude-time sections of the 1979-2012 climatology of the zonal mean stratopause pressure (bottom) and stratopause temperature (top) made with monthly mean MERRA data. Tick marks on the horizontal axis denote the first day of each month

the solar flux and hence the ozone photolysis is maximum: over the summer pole at the solstices, over the equator at the equinoxes. The polar stratopause temperature decreases during the autumn because the polar night does not allow the ozone photolysis in the stratosphere. In agreement with Kanzawa (1989), the polar winter stratopause is warmer in the southern hemisphere than in the northern hemisphere because the latter is affected by stronger PW breaking in the upper stratosphere which leads to a stronger weakening of the vortex, enhanced ascents of stratospheric air and acts to cool the stratopause (with respect to thermal wind). The highest stratopause (i.e. lowest pressure) is located over the winter pole because it is maintained by gravity wave driven descent in the mesosphere at higher altitudes (Hitchman et al. 1989). This high stratopause is warmer than the winter hemisphere mid-latitude one where both the ozone heating and gravity wave driven vertical motions are weak. This phenomenon is more visible during the southern hemisphere winter because of a stronger vortex and weaker PW activity over Antarctica. Focusing on the low latitude stratopause, a 'bump' can be observed in January over the equator (local stratopause pressure maximum) and will be more discussed later. Tomikawa et al. (2008) had observed a wintertime (January in the northern hemisphere, June in the southern hemisphere) temperature maximum of $270 \mathrm{~K}$ at the subtropical winter stratopause (between 15 and 30 latitude degrees) in a T213L256 Global Circulation Model. This climatological temperature maximum at the stratopause was explained to be due to a downwelling of the meridional circulation from the summer tropics to the winter subtropics passing above the stratopause. However, such a temperature maximum is not visible in our MERRA climatology of the stratopause presented on Fig. 1 and is also not visible in the climatology of the stratopause in France et al. (2012).

Figure 2 presents the 1979-2012 climatology of the Arctic stratopause pressure using MERRA monthly data. This climatology (Fig. 2) agrees well with the MLS climatology shown in France et al. (2012), notably the formation of the higher polar stratopause during $\mathrm{NH}$ winter. It is correlated with the vortex enhancement and the cooling of stratospheric air (in accordance with the thermal wind law). The height of the polar stratopause increases from $0.9-1 \mathrm{hPa}$ in August to $0.1-0.2 \mathrm{hPa}$ in November-December-January and February. It is highest in November because of an increase in the breaking height of gravity waves due to the strengthening of the vortex and weaker PW activity than in December, January and February.

The winter polar stratopause temperature is zonally asymmetric and presents an obvious temperature minimum (about $20 \mathrm{~K}$ colder than the ambient air) above the Aleutian Islands especially visible in January and February. Indeed, a quadrature can be observed in January between the minimum of stratopause pressure over Greenland, the highest stratopause pressure over eastern Siberia (Fig. 2, January), the stratopause temperature minimum over the Aleutian Islands, and the stratopause temperature maximum over north Europe (not shown). This is consistent with the climatological wave-1 structure in winter described by France et al. (2012).

Figure 3 shows a time series of the equatorial $(5 \mathrm{~N}-5 \mathrm{~S})$ zonal wind and of the equatorial stratopause (green line) from 1979 to 2012 for MERRA daily data. It shows that the equatorial bump (observed in Fig. 1) is mainly present in January but is also sometimes present in June (June 2010 for instance). Furthermore, a good correlation is present between the equatorial stratopause height and the Semi-Annual Oscillation (SAO). During the easterly phase of the SAO in January and June one can observe an ES. During the westerly phase of the SAO, the equatorial stratopause drops especially when the $1 \mathrm{hPa}$ westerly wind propagates downward to join the westerly QuasiBiennal Oscillation (QBO). These elevations of the stratopause are probably linked to the equatorial upwelling during the easterly phase of the SAO. The easterly phase of the SAO in January is well known to be stronger than in June. The easterly phase of the SAO is believed to be primarily driven by the advection of summer easterlies by 


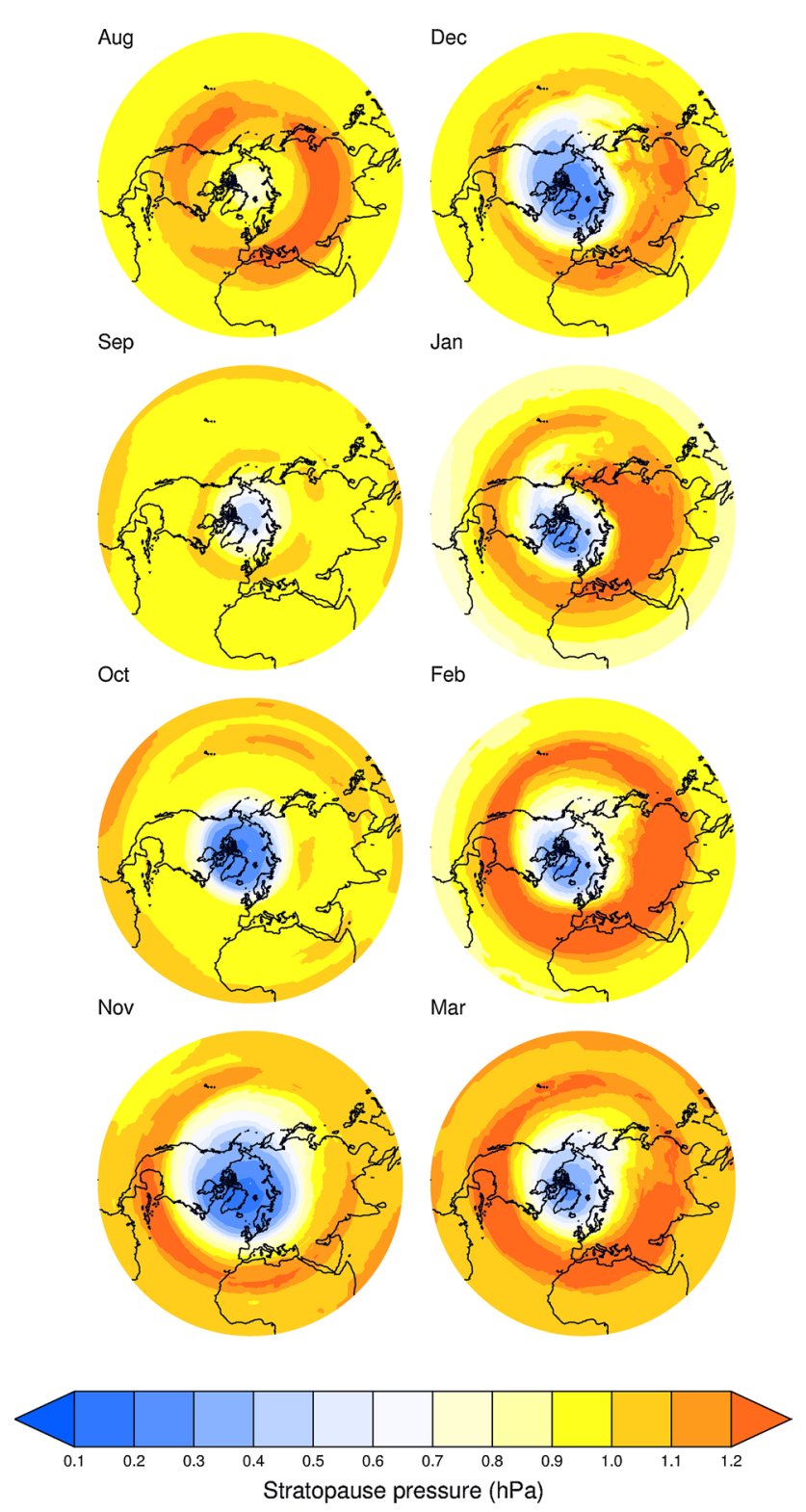

Fig. 2 1979-2012 Climatology of the Northern Hemisphere stratopause pressure using MERRA monthly data. Only NH winter months (August to March) are displayed

the Brewer-Dobson circulation, which is stronger in January than in June because of increased PW forcing in the Northern Hemisphere associated with increased orographic forcing (Andrews et al. 1987). Interestingly, the amplitudes of the stratopause depressions from 2001 and the easterly SAO phase during the last decade in the MERRA data are stronger, suggesting an increase in the strength of the Brewer-Dobson circulation (Shepherd and McLandress 2011).

The good agreement between the France et al. (2012) MLS climatology and our MERRA climatology support the analysis of the stratopause in these reanalysis data. Hence, we will now focus on the northern hemisphere stratopause and particularly on its behaviour during SSWs.

\subsection{The stratopause during SSWs}

\subsubsection{Comparisons with satellite data}

In this section the representation of the stratopause during sudden stratospheric warmings is assessed in the MERRA dataset by comparison with satellite observations. Figure 4 shows the daily northern polar cap temperature (averaged over $70-88^{\circ} \mathrm{N}$ ) from the MERRA (bottom), MLS (middle) and HIRDLS (top) datasets for the period 2004-2012. All three data sets show that, during an SSW event, a warm temperature anomaly (red) quickly propagates downward from the upper winter stratosphere to the mid-low stratosphere. Subsequently the polar stratosphere becomes nearly isothermal and the normal winter stratospheric state reappears a few days later. The stratopause (green line) follows well the quick downward propagation of warm anomalies and abruptly drops during the events. Then it soars either to an altitude higher than before the event (after the 2006 warming for instance) or to around its normal winter altitude. Mesospheric coolings which matches the stratospheric warmings can be seen with thin dark-blue strips at mesospheric altitudes during the SSWs. No obvious conclusion about possible differences of the polar cap stratopause behaviour between displacement and splitting events can be drawn with this plot.

The fact that one ES event is preceded by a splitting event (2009) and one is preceded by a displacement event shows that the occurrence of an ES is probably not dependant on the type of SSW event. This agrees with the results of Chandran et al. (2013).

Comparing the three datasets, one can see that the polar cap stratopause is similar in the three datasets in summer and in relatively undisturbed winters (e.g. 2004/2005, $2006 / 2007$ and 2007/2008 winters). However, when the middle atmosphere is affected by strong SSW events e.g. in 2005/2006, 2008/2009, 2009/2010 and 2011/2012, the stratopause drop just after the onset date is under-estimated in the MERRA dataset. In particular, the ES formation after the strong 2006 vortex displacement and the strong 2009 vortex splitting is not represented in the MERRA data as observed in Manney et al. (2008). Figure 5 explores these issues further by showing the difference between polar cap temperature for the MERRA and MLS data for 30 day periods either side of the $5 \mathrm{SSW}$ events shown in the previous figure. There is an underestimation of the downward propagation of the upper stratospheric warming in the MERRA data set, where the disturbed mid-stratosphere is colder by $\sim 15 \mathrm{~K}$ before the SSW than MLS. In the mesosphere the MERRA analysis is too warm, underestimating the 
mesospheric cooling (by about $20 \mathrm{~K}$ ) in the MERRA data before the SSWs. Both these differences, and the subsequent underestimation of the stratopause descent are probably due to an imperfect parametrization of GWs [probably insufficient consideration of small scales GWs (Garcia and Boville 1994)] in the middle atmosphere in GEOS-5, the model used for the data assimilations for the MERRA dataset.

Two principle explanations for these differences and the poor representation of the ES can be found. Given that the GEOS-5 model has an upper limit at $0.02 \mathrm{hPa}(\sim 75 \mathrm{~km})$, it can clearly not reproduce a stratopause above this. Moreover, the ES events have been associated with non-orographic GW drag (Wright et al. 2010; Chandran et al. 2011; Limpasuvan et al. 2012; Tomikawa et al. 2012; Yamashita et al. 2013) so poor parametrization of GWs in GEOS-5 at high altitudes could be another reason for the absence of ES events and for the errors in the middle atmosphere representation after the warmings in MERRA data (Manney et al. 2008). Other factors that may play a significant role include radiation calculations and bias correction in data assimilation during the creation of reanalysis data (Manney et al. 2008). This is especially true near the stratopause area where very little data are used in the assimilation. Nevertheless, even if the MERRA dataset cannot fully reproduce the extreme stratopause behaviour, it can help to understand several of its features during SSW events.

\subsubsection{The zonal mean stratopause during vortex splitting and displacement events}

In order to identify anomalies during SSW events, a daily climatology of temperature, zonal wind, geopotential height, E-P flux diagnostics, stratopause pressure and stratopause temperature has been made using all the available data between 1979 and 2012 (Figs. 6 and 7 for displacement and splitting events, respectively). Significance is assessed using a Monte-Carlo algorithm with 10,000 resamples of winter days over the last 34 years that are not affected by a SSW.

Figures 6 and 7 show the anomalies at the onset dates of the SSW (plus/minus one day; denoted -1_1) and 3 day averages up to 21 days before and after the SSW, so that the evolution can be observed. A clear dipole of temperature anomalies (Figs. 6a and 7a) appears over the high latitudes in both types of warming: a positive anomaly in the high latitude stratosphere and a negative in the high latitude mesosphere. It is statistically more significant for the displacement events. A corresponding anomaly develops over the same period in geopotential height (row B) and zonal winds (row $\mathrm{C}$ ) as expected. The warm anomaly is associated with a downwelling (Figs. 6d and 7d) over the polar region while the cold anomaly is associated with an upwelling in the residual circulation anomalies in agreement with Matsuno (1971); Zülicke and Becker (2013). This polar temperature dipole onset matches the onset of a positive geopotential height anomaly (Figs. $6 \mathrm{~b}$ and $7 \mathrm{~b}$ ) associated with the Aleutian high enhancement and poleward shift (Harvey and Hitchman 1996).

For the displacement events temperature anomaly (Fig. 6a) the clear high latitude temperature dipole is associated with a weaker (but also significant) temperature anomaly dipole over the mid-latitudes. The dipole structures are opposite in sign. This mid latitude anomaly must be a consequence of the equatorward shift of the vortex during displacement events (i.e. the negative geopotential anomaly on Fig. 6b) and the associated modifications of the temperature field (via thermal wind balance). The latitudinal extent of the anomalies associated with a SSW does not only depend on the nature of the SSW (displacement or splitting). The zonal mean polar temperature and the zonal wind anomalies are stronger and more significant for the displacement events than for the splitting events. The high latitude zonal mean stratopause is lower than the climatological one during both the SSW types (black line on all plots). It decreases inside the positive geopotential anomaly, with the polar downwelling of the residual circulation and the enhancement of the polar temperature dipole. This decrease is clearly enhanced for displacement events (Fig. 6b) over splitting events (Fig. 7b).

Figures $6 \mathrm{e}$ and $7 \mathrm{e}$ show that both splitting and displacement events are associated with an enhanced negative E-P flux divergence at high latitudes in the middle atmosphere. This convergence of E-P flux is principally due to the PW breaking, and the anomalies descend downward from the upper stratosphere to the mid-low stratosphere following the filtering of large scale stationary planetary waves at the zero wind line (Matsuno 1971). Given that such waves can not propagate if the zonal wind is westward (Charney and Drazin 1961), their breaking occurs at progressively lower altitudes. The changes of the zonal wind field modifies the refractive index of Rossby waves and makes the E-P vectors more vertical and poleward around the onset dates of both the splitting and displacement events. This suggests that PWs are being diverted from their climatological equatorward propagation (Andrews et al. 1987). When the zero wind line reaches the lower stratosphere, the PWs cannot propagate vertically anymore and the E-P flux convergence in the stratosphere drops. A continuous bombardment of planetary waves disturbs the middle atmosphere from at least 20 days before the onset date to 5 days after the displacement events. To the contrary, splitting events are more characterized by a shorter (around days 0-5) but stronger EP flux convergence (Figs. 6e and 7e).

If we consider the period immediately following the warming peak, a positive E-P flux divergence above 

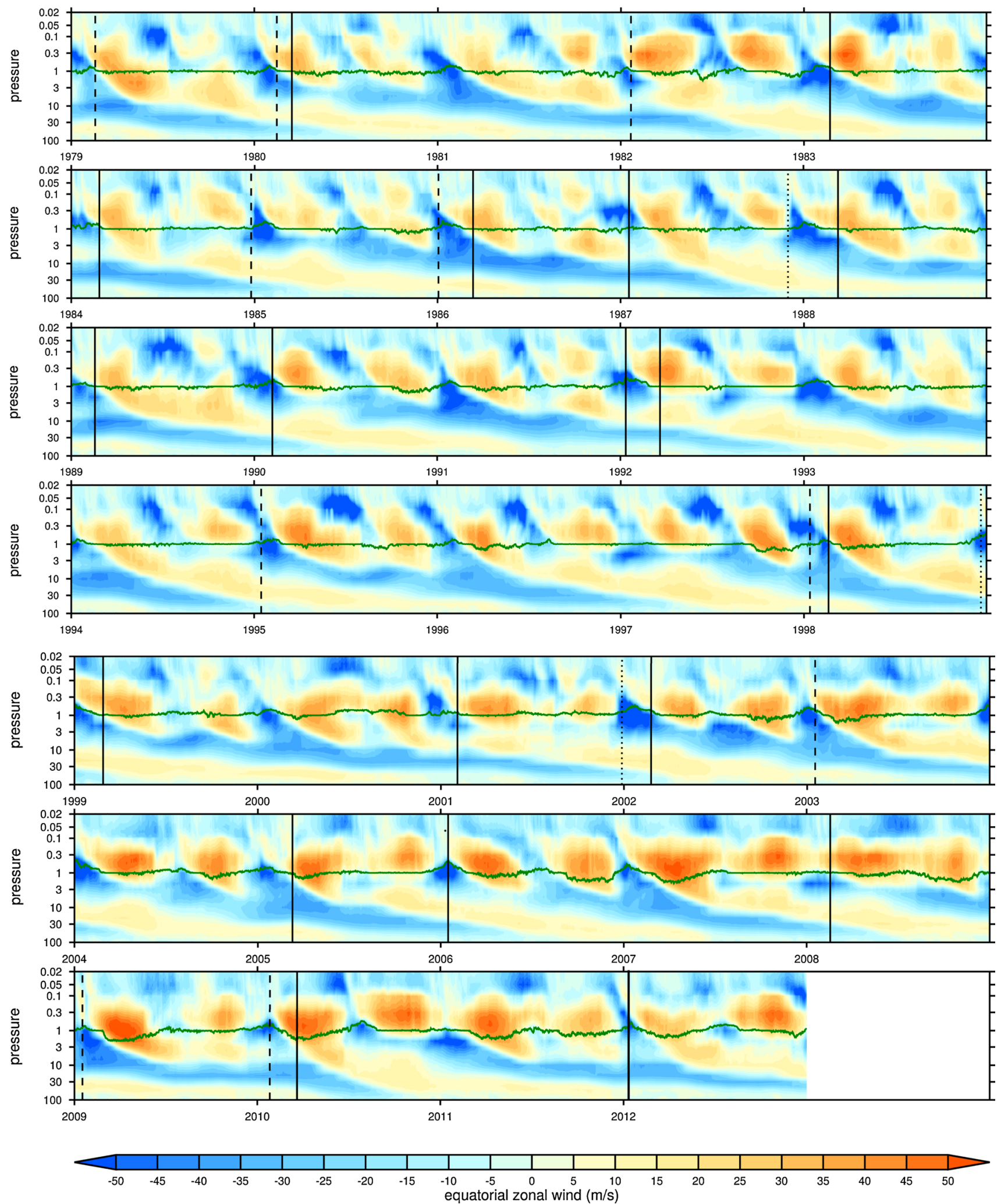

Fig. 3 Time series of the equatorial zonal wind (mean between -5 and 5 latitude degrees) in the MERRA daily data from 1979 to 2012. The equatorial stratopause is plotted in green. Tick marks on the horizontal axis denote the first of January of each year. Thick (dashed) lines show the central date of the displacement (splitting) events according to Mitchell et al. (2013). Dotted lines show 'mixed' events (i.e. when a SSW can not be defined as a split or as displacement event, it is called a 'mixed' event (Mitchell et al. 2013)) 


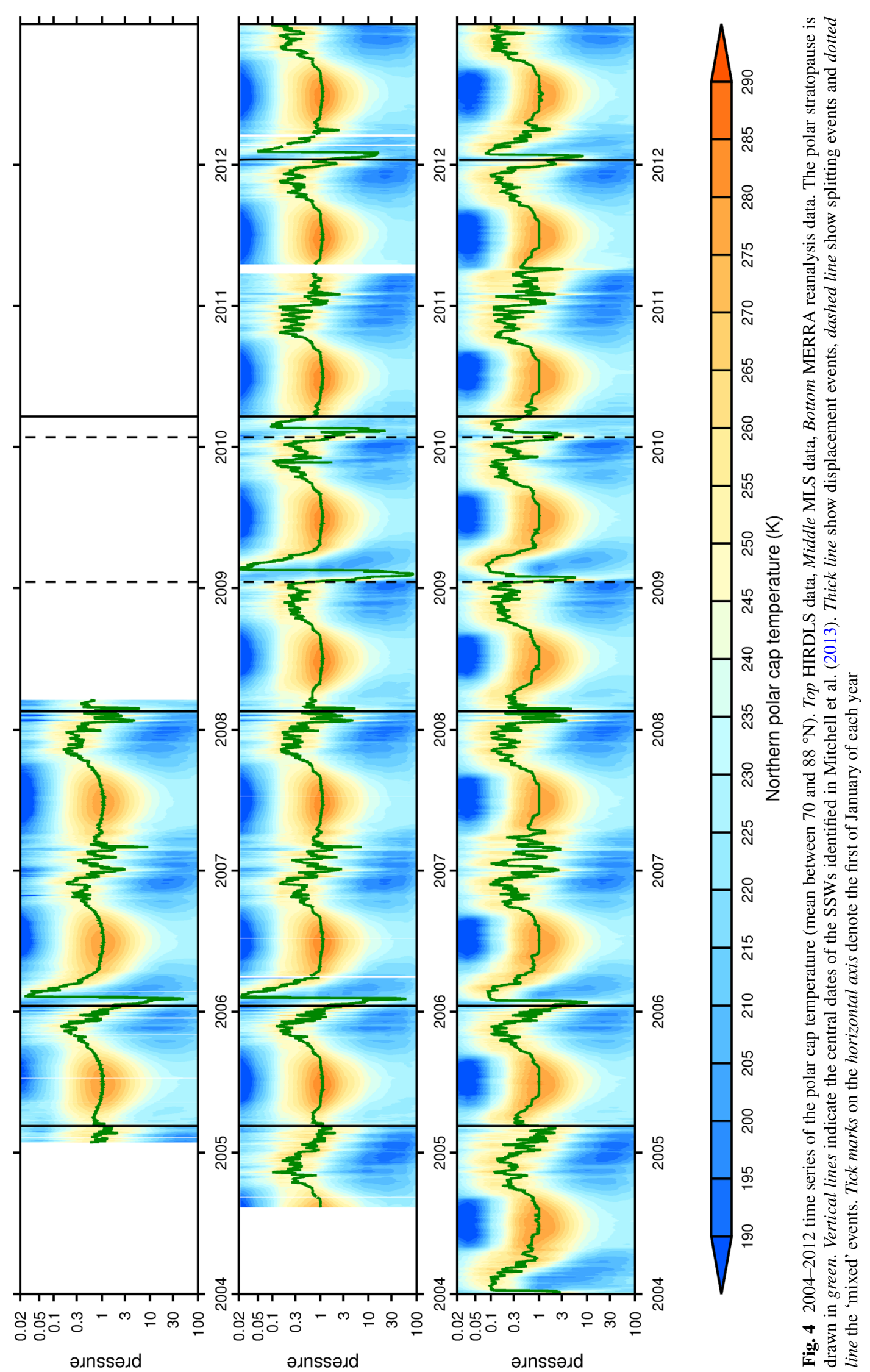




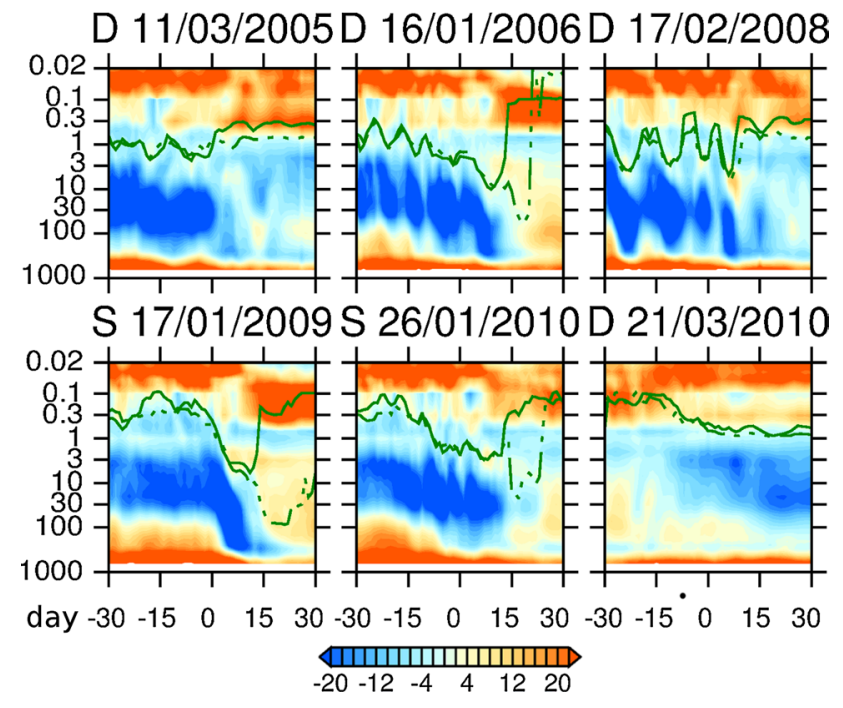

Fig. 5 Time series of the difference MERRA data minus MLS data of the polar cap temperature in Kelvin (mean between $70 \mathrm{~N}$ and $88 \mathrm{~N}$ ) during five SSWs. The onset date of each event is above the plots and is preceded either by the letter $S$ if the SSW is a splitting, or a letter $D$ if the SSW is a displacement event. The polar stratopause identified in MERRA data is plotted in the thick green line, the MLS one is plotted in the dotted green line. Tick marks on the horizontal axis denote the relative day compared with the onset date of the event. Pressure on the $\mathrm{y}$-axis is in $\mathrm{hPa}$. Temperature is in $\mathrm{K}$

$0.3 \mathrm{hPa}$ can be observed (days 11-13 on Fig. 6e and 7e). However, it is only persistent for the displacement events (Fig. 6e days 19-21). This observation is in agreement with Tomikawa et al. (2012) who showed mesospheric zonal wave number $1 \mathrm{PW}$ activity after a vortex displacement event generated by baroclinic and barotropic instabilities. The same result was also reported in Smith (1997) but was attributed to asymmetries in the GW drags. The later positive EP flux divergence associated with this mesospheric PW activity and the cooling generated by eastward GW breaking (Chandran et al. 2011) accelerates the zonal wind at mesospheric altitudes and helps the polar night jet to recover at a higher altitude than before the warming. In a zonal mean view, this is only really noticeable for the displacement events (i.e. Fig. 6c on days 19-21) with a positive zonal wind anomaly between 1 and $0.02 \mathrm{hPa}$ at $60 \mathrm{~N}\left(10 \mathrm{~ms}^{-1}\right)$. This also explains why the negative zonal wind anomaly associated with the SSW on Figs. $6 \mathrm{c}$ and $7 \mathrm{c}$ is more persistent during splitting events. During displacement events, the higher-than-usual vortex recovery is also associated with a positive zonal mean stratopause height anomaly over the pole from day 13 for around 10 days. This is particularly visible over day 19-21 on Fig. 6. In summary, the vortex appears to take longer to recover to its climatological state after split SSW events than after displaced events.

\subsubsection{Zonal asymmetries of the disturbed stratopause}

The differences between the stratopause during splitting and displacement events are more evident when considering zonal asymmetries because the evolution of both types of event are inherently asymmetric. Figure 8 shows composites during displacement events of stratopause pressure (top) and $1 \mathrm{hPa}$ geopotential height (bottom). Immediately clear is an enhancement of the wave- 1 structure from the climatological winter stratopause. For example at 19-21 days before onset in the GPH field (it bottom row) the polar vortex (negative anomaly) is displaced off the pole and the Aleutian High (positive anomaly) gradually grows in magnitude over time and moves poleward so that by the onset the Aleutian High has replaced the polar vortex and is centred over the pole. There is a good correlation between the variations in the stratopause pressure (Fig. 8, top) and the variations in geopotential height anomaly (Fig. 8, bottom). The baroclinic structure related to the wave-1 PW propagation is particularly visible on the longitudinal cross section of the temperature anomalies field at $60 \mathrm{~N}$ at the onset date of the displacement events (Fig. 9, top left panel). The remnants of the polar vortex (pink negative contours) are present at lower altitudes but the dominant feature is now the Aleutian High (green positive contours). In order to determine if the ageostrophic circulation which governs the climatological stratopause temperature pattern [shown in France and Harvey (2013)] is also responsible for the stratopause temperature anomalies during displacement events, the anomalies of the ageostrophic circulation in the MERRA data are also plotted on Fig. 9. Moreover, one can consider the conservation equation for potential temperature:

$\frac{D \theta}{D t}=\frac{J}{C p} \frac{\theta}{T}$

It can also be written as follows:

$\frac{\partial T}{\partial t}=-\left(u \frac{\partial T}{\partial x}+v \frac{\partial T}{\partial y}+\Omega \frac{\partial T}{\partial p}\right)+\frac{\Omega}{\rho C p}+\frac{J}{C p}$

where $\theta$ is the potential temperature, $T$ the temperature, $u, v, w$ the three components of the wind, $P$ the pressure, $C p$ the isobaric heat capacity per unit mass of dry air and $J$ is the diabatic heating rate per unit mass. Here, $\Omega=\frac{D P}{D t}$ . Hence, the temporal evolution of the air temperature depends on:

- the horizontal air advection term $\left.-\left(u \frac{\partial T}{\partial x}+v \frac{\partial T}{\partial y}\right)\right)$

- the vertical air advection term $\left(-\Omega \frac{\partial T}{\partial p}\right)$

- the adiabatic heating rate related to the air parcels compression/dilatation $\left(\frac{\Omega}{\rho C p}\right)$

- the diabatic radiative heating rate $\left(\frac{J}{C p}\right)$. 
$-21-19$

$-13-11$

$-5-3$

a Temperature anomaly $(\mathrm{K})$
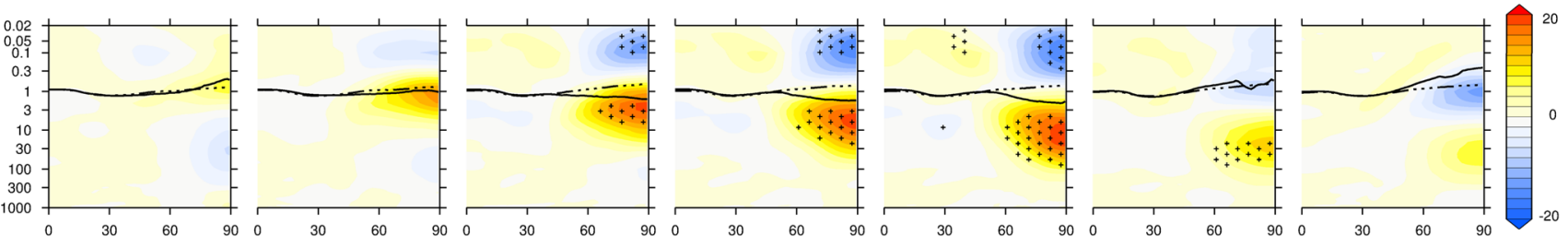

b geopotential height anomaly $(\mathrm{m})$
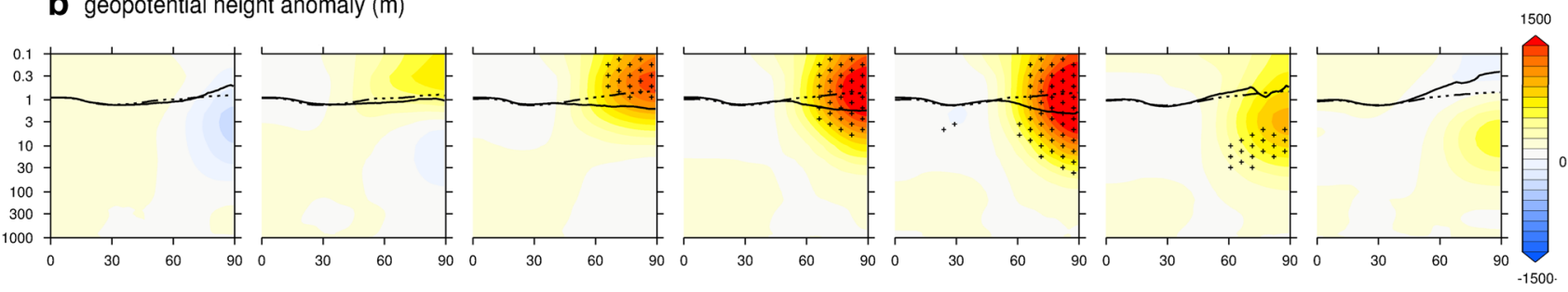

C zonal wind anomaly $(\mathrm{m} / \mathrm{s})$
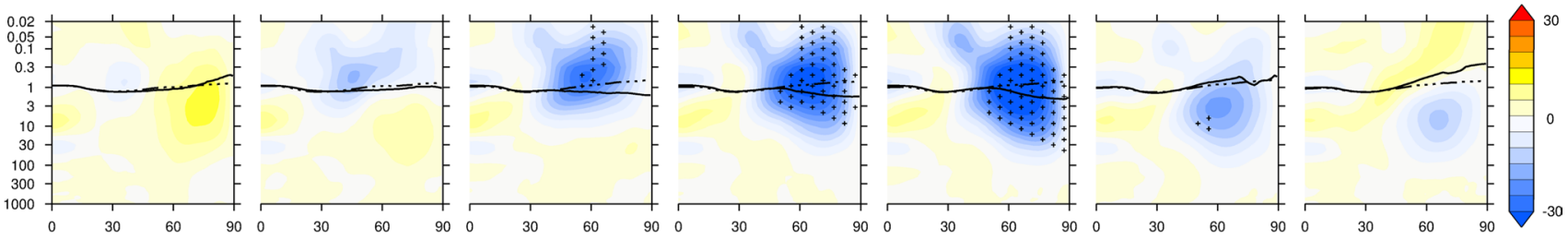

d Residual circulation stream function $\left(\mathrm{m}^{2} / \mathrm{s}\right)$
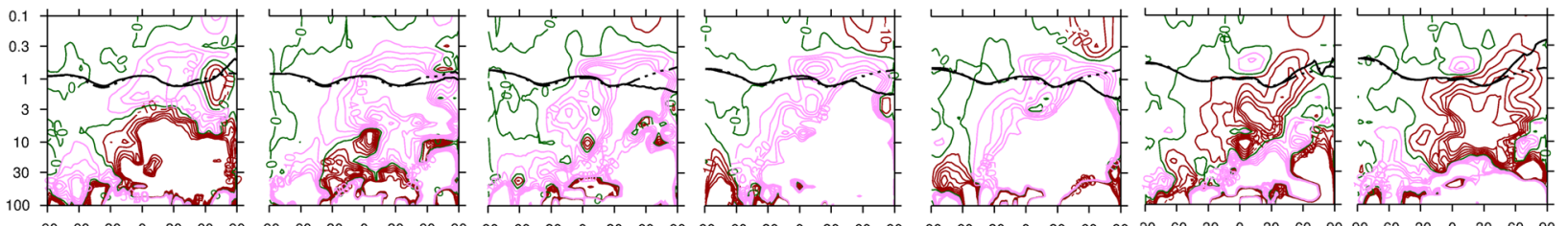

$\operatorname{divF}$ anomaly $(\mathrm{m} / \mathrm{s} /$ day $)$
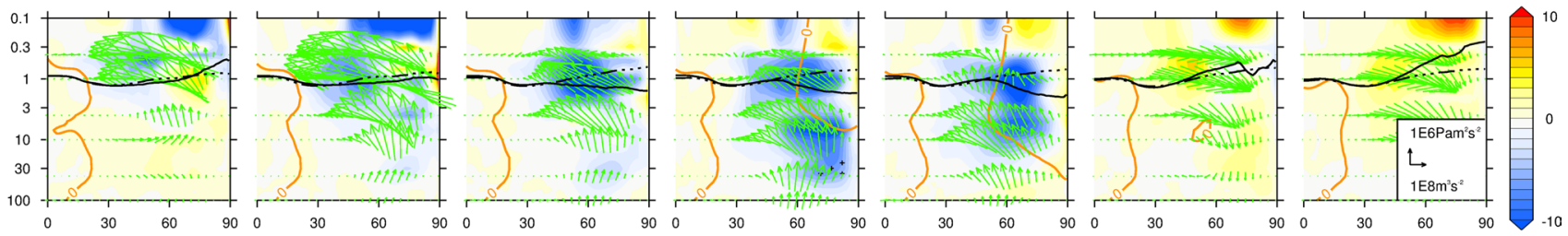

Fig. 6 Pressure-Latitude cross section of composites for the zonal mean temperature (a), zonal mean geopotential height (b), zonal mean zonal wind (c), residual circulation (d) and E-P flux divergence (e) anomalies for the displacement events composite analysis (carried out with MERRA data). Each plot shows a 3-day mean. The number above the plot indicates lag/lead from what days comparing to the central date (number 0 ) have been used to do the 3-day mean. The composite stratopause is plotted with a thick black line, the climatological one is plot with a dashed line. The crosses on plots $\mathbf{a}, \mathbf{b}, \mathbf{c}$ and e show the regions where the anomalies are significant compared with the climatology (95\% level using a Monte Carlo resampling). For the

The anomalies of these four contributions to the air heating (compared with a climatology) are plotted on Fig. 9. One can observe that to the first order, the warm anomalies between 3 and $10 \mathrm{hPa}$ are located where the ageostrophic residual circulation, pink lines (negative stream function anomalies) show clockwise residual circulation anomalies. Green lines show nul residual anomalies and brown lines show anti-clockwise residual circulation anomalies. In panel E, the red line shows the zero wind line and green arrows the E-P flux. E-P flux vectors and divergence are divided by $(\rho a \cos \phi)$ (with $a$ the Earth radius, $\rho$ the air density and $\phi$ the latitude) in order to display the whole acceleration term by the waves in the transformed Eulerian mean equations (Andrews et al. 1987). Panels $D$ and $E$ focus specifically on the stratosphere (i.e. the $\mathrm{y}$-axis is different from panels $A-C$ )

circulation is downward and where the adiabatic heating rate associated with the compression of air is maximum (Fig. 9) and vice versa. The adiabatic heating rate and the horizontal air advection have similar amplitudes and are 
$-21-19$

$-13-11$

$-5-3$

$-1$

35

1113

1921

a Temperature anomaly $(\mathrm{K})$
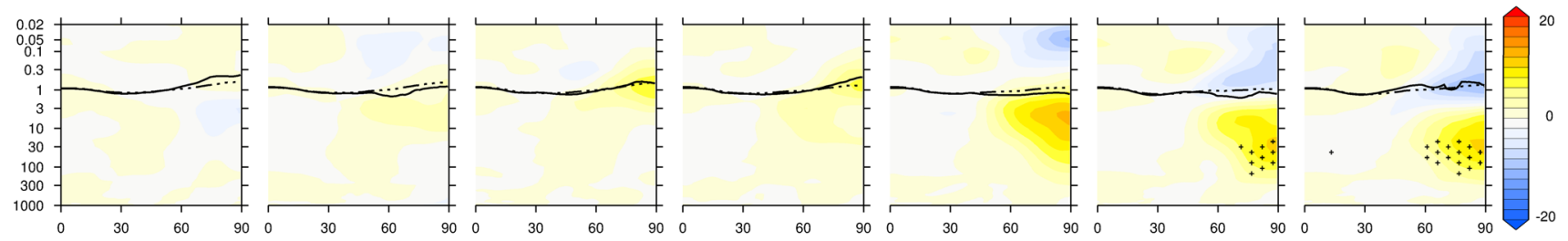

b geopotential height anomaly $(\mathrm{m})$
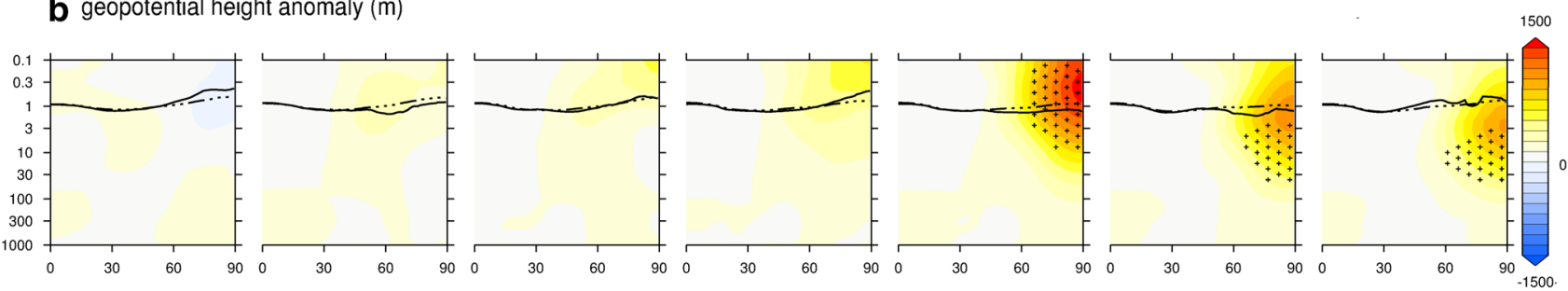

C zonal wind anomaly $(\mathrm{m} / \mathrm{s})$
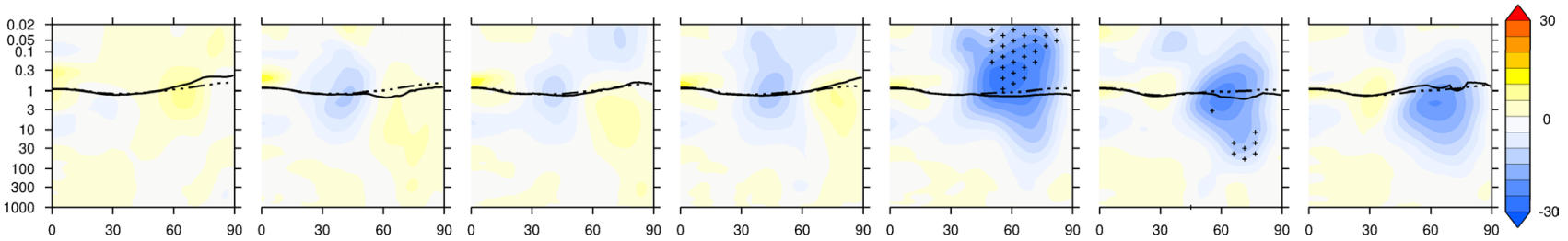

d Residual circulation stream function $\left(\mathrm{m}^{2} / \mathrm{s}\right)$
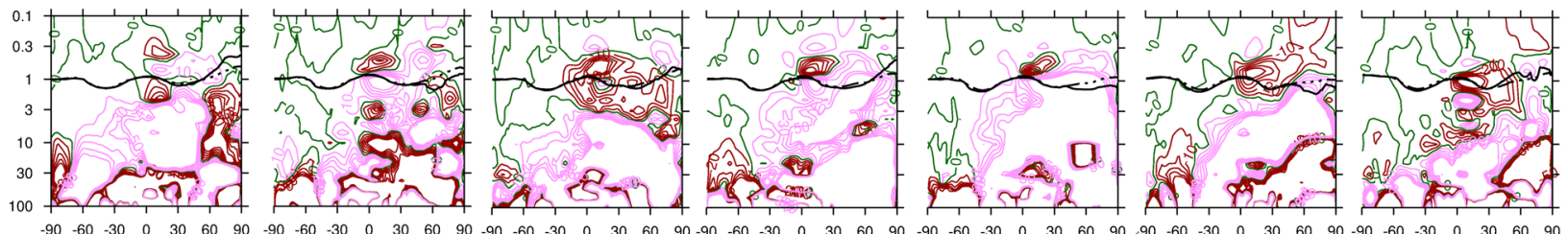

e $\operatorname{divF}$ anomaly ( $\mathrm{m} / \mathrm{s} /$ day)
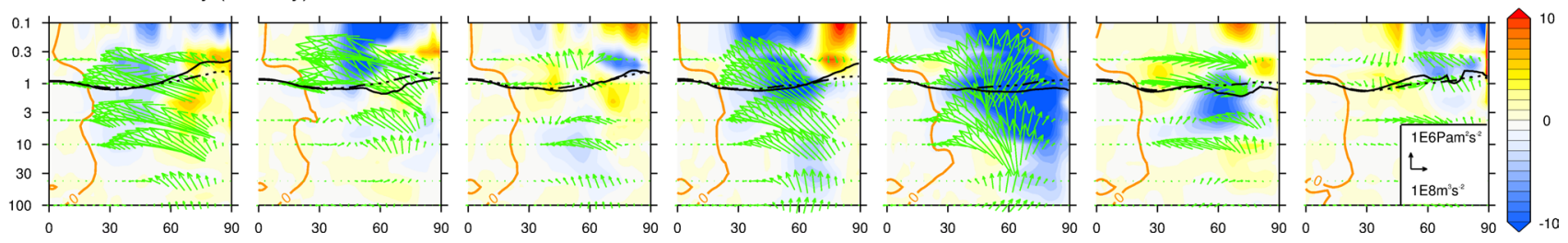

Fig. 7 As in fig. 6 but for the splitting events composite analysis

opposite in sign. That means the heating and cooling in the upper stratosphere-lower mesosphere generated by the air compression and dilatation are strongly limited and modulated by the horizontal advection which smooths the temperature anomalies (and also to a lesser extent by the diabatic cooling especially in the mesosphere). The anticorrelation between diabatic heating rate and temperature anomalies agrees with the observation of France and Harvey (2013).

Finally, the composite stratopause at the displacement events onset date (thick black line on Fig. 9, left top panel) is warmest at the western edge of the positive geopotential height anomaly where there is an ageostrophic air descent. It follows the warm temperature anomalies to the inflexion of the iso-lines of geopotential height anomalies at the center of the anticyclone where the GWs cannot maintain it. Therefore, the stratopause is low inside the anticyclone. At the western edge of the negative geopotential anomaly, the stratopause raises because of the cold temperature due to air rising and dilatation. Its height is maximum inside the vortex where the GW driven descents maintain it. The conclusion of France and Harvey (2013) that vertical ageostrophic motions are at the origin of the climatological stratopause temperature anomalies during winter can thus be 

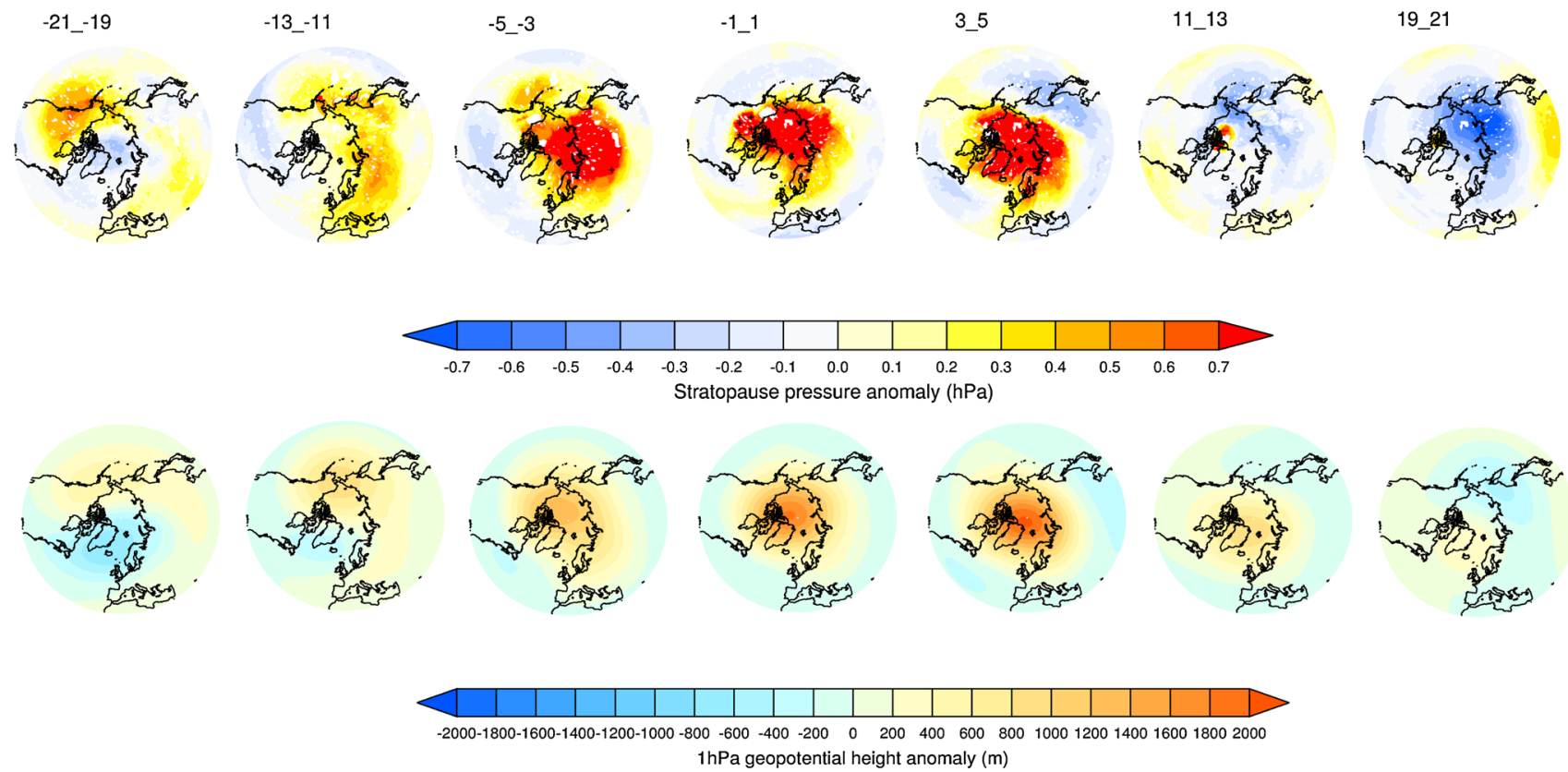

Fig. 8 Stereographic maps of different times throughout the lifecycle of composites for the displacement events composite analysis (carried out with MERRA data). Each panel shows a 3-day mean. Numbers above the panels indicate time since the displacement onset date (what days comparing to the central date (number 0 ) have been used

extended to the stratopause temperature pattern during displacement events.

Figure 10 is the same as Fig. 8 but for splitting events. The wave-2 structure which characterizes the splitting events can be observed in the geopotential height anomaly field (bottom row). The principle difference between splitting and displacement events is that splitting events have a more barotropic structure, observed in Fig. 9 (bottom left panel) in agreement with Matthewman et al. (2009). The decrease in stratopause height is still located with the positive geopotential height anomalies, and the temperature anomaly minima are located at the eastern edge of a cyclone anomaly where the ageostrophic vertical motion anomaly is upward while the temperature anomaly maxima are located at the eastern edge of an anticylone anomaly where the ageostrophic wind anomaly is downward (Fig. 9, bottom left panel). Like during displacement events, the compression of air associated with the ageostrophic vertical motions related to PW propagation (Fig. 9, bottom) generates the warm anomalies in the upper stratospherelower mesosphere. These latter are reduced and modulated especially by the air advection in the stratosphere and mesosphere and a little by the diabatic heating (Fig. 9, bottom) in the mesosphere. Moreover, the amplitude of the four heating rate contributions are higher during the splitting event onset date than during the displacement events one. This is consistent with the shorter and stronger EP to do the 3-day mean). The top row of figures show the stratopause pressure anomaly from the climatology. The bottom row is the $1 \mathrm{hPa}$ geopotential height anomaly. The white dots in the top panels are places where the stratopause have not been detected by the algorithm

flux convergence in the stratosphere for the splitting events noted previously.

No major difference in the amplitude of the stratopause temperature anomalies between splitting and displacement events can be observed. However, the positive anomaly of stratopause pressure related to the drop inside the anticyclones is higher for the displacement events than for the splitting events. Moreover, after the two types of SSW (days 19-21 on Figs. 8 and 10), a negative stratopause pressure anomaly (i.e a high stratopause) is noticeable over eastern Siberia and matches a negative $1 \mathrm{hPa}$ geopotential height anomaly. Indeed, this latter shows the vortex recovery and allows an easier propagation of westward and stationary GWs and so, a higher breaking and stratopause generation. The amplitude of the negative stratopause anomaly is smaller after the splitting events and that is why it has only been observed for displacement events in the zonally averaged study in the last subsection. Its location is not the same as the location of the ES formation [over Canadian Arctic according to France and Harvey (2013)] and is still an issue to explore.

Finally, the stratopause pressure anomalies are not significantly different from the climatology at the $95 \%$ level. This is due to the high variability in stratopause height during winter time (i.e. due to a high frequency of minor sudden stratospheric warmings). In addition, the lack of significant stratopause anomalies during vortex splitting and 


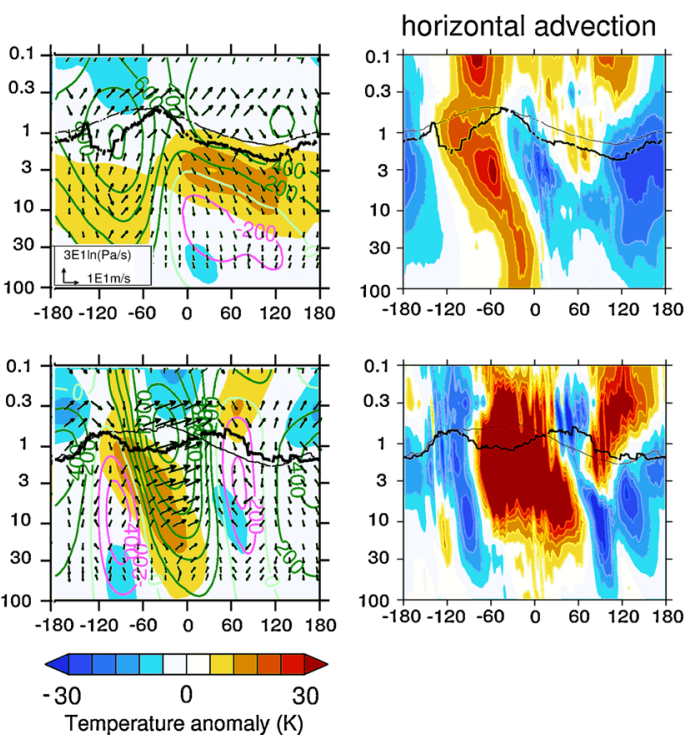

Fig. 9 Longitude-Pressure cross section at $60 \mathrm{~N}$ of the temperature anomaly (left panels) and of the four contributions to the air heating rate for the displacement (top) and splitting (bottom) event composites (MERRA data). The panels show a 3 days mean around the onset date. The thick black line shows the composite stratopause and the

displacement events will be in part due to the inability of GEOS-5 (the underlying model used for the data assimilation of MERRA data) to well represent the gravity waves (shown in Sect. 3.2.1).

\section{Conclusion}

The MERRA reanalysis data have been used to calculate a 34-year climatology of the stratopause with a specific focus on 20 vortex displacement events and 10 vortex splitting events. A comparison between MLS, HIRDLS and MERRA data has been performed to evaluate the quality of the stratopause identification in the MERRA dataset. Although the three datasets agree well for the undisturbed stratopause, when the stratopause becomes strongly disturbed, several differences appear. An underestimation of the drop during strong SSWs and the absence of the 2006 and 2009 ES events are noticeable in the MERRA data comparing with the satellite data. It is likely due to a too low cap limit or to a poor parametrization of GWs in the GEOS-5 model. Moreover, to look at MLS data has also shown that ES events can occur after a displacement event (in 2006) and after a splitting event (2009) in agreement with Chandran et al. (2013). However, the primary stratopause structures, such as the separated zonal mean polar stratopause in winter, and the wave- 1 pattern of the stratopause, can clearly be identified. As in France et al. (2012), the climatological stratopause in winter is low in thin one the climatological stratopause. The green and pink contours on the left panels indicate positive and negative geopotential height anomalies respectively. The black arrows show the ageostrophic wind anomalies comparing with the daily climatology. The logarithm of the vertical component is displayed to make it more visible

the anticyclones and high in the vortices. A correlation between the equatorial stratopause altitude and the SAO was observed and it seems to be modulated by the QBO. Indeed, the equatorial stratopause depressions are particularly dramatic when the SAO westerly winds propagate downward to join the westerly QBO (Ern et al. 2014). This is the first study which has considered this phenomenon.

The composite analysis of displacement and splitting events has allowed to highlighted several differences between the two types of SSW, not only for the stratopause but also for the whole middle atmosphere. The structure of the high latitude winter stratopause closely depends on the PW activity and its consequent residual circulation anomalies. While during a displacement event, the upper stratosphere undergoes a persistent PW forcing which starts around 15 days before the onset date, during the splitting events it is affected by a quick (a few days) bombardment of PWs around the onset date. The subsequent downwelling over the pole associated with a positive geopotential anomaly makes the zonal mean polar stratopause descent. This zonal mean stratopause drop is deeper and the zonal mean temperature and zonal mean zonal wind anomalies are more statistically significant for the displacement events than for the splitting events. Moreover, just after the displacement events, an upper stratosphere-lower mesosphere EP flux divergence dipole appears and helps the recovery of the vortex at higher altitudes. This leads to a high zonal mean stratopause anomaly over the pole. This phenomenon is not really noticeable for the splitting events. 

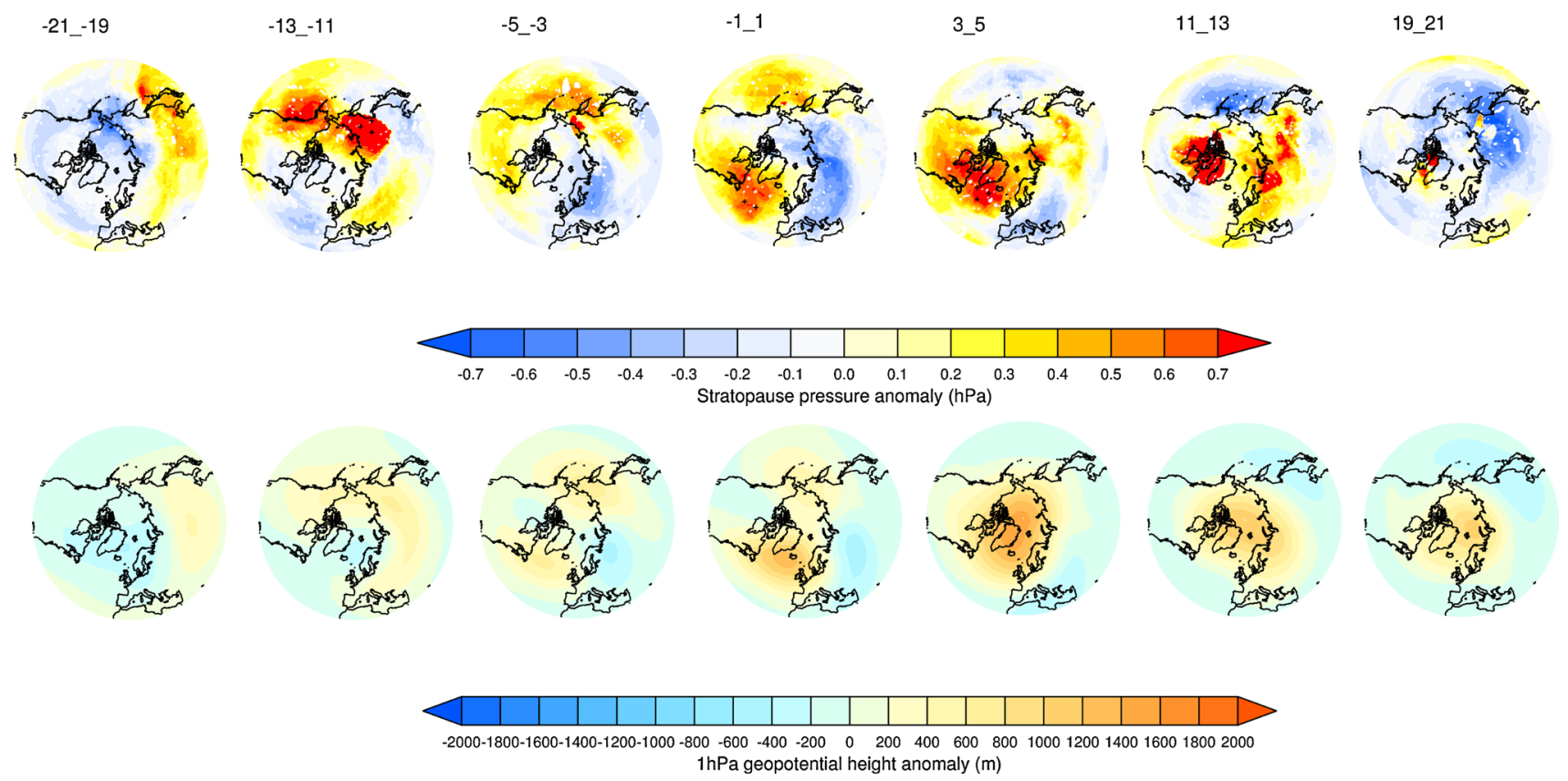

Fig. 10 As in Fig. 8 but for splitting events

In fact, a restriction to a zonal mean view hides important asymmetries. While the stratopause during displacement events presents a wave- 1 structure, the stratopause during the splitting events evolves into a wave- 2 structure. In both the cases the high stratopause anomalies are located inside the negative geopotential anomalies and vice versa. The ageostrophic motions explain well the temperature anomalies of the stratopause during the two types of SSW and extend the conclusions of France and Harvey (2013) for the climatological stratopause to the stratopause affected by SSWs. Furthermore, a positive stratopause height anomaly about 20 days after the warmings exists in the two composite analyses and is located over eastern Siberia. It matches the recovery of the polar night jet after the SSWs and only projects onto the zonal mean view for the displacement events.

Future work needs to focus on the equatorial stratopause, in order to understand exactly how the equatorial stratopause behaves and what dynamical processes its behaviour can help us to understand. Moreover, the exact mechanism which generates the mesospheric PWs after the displacement events is still not understood and Fairlie et al. (1990) further mention that inertio-GWs may be generated near the baroclinic zones in the winter stratosphere. Hence, an extended study on the ageostrophic circulation during the two types of SSW would also be of interest to understand a possible GW generation in the middle atmosphere and perhaps may help to understand the ES dynamics and occurrence.
Acknowledgments The authors thank the two anonymous reviewers for their insightful comments. Thanks also to Lesley Gray for her constructive comments and helpful discussions, Corwin Wright for providing satellite data and Michael Bosilovich for help in acquiring the non-standard levels for the MERRA data. Thanks to the Global Modeling and Assimilation Office (GMAO) and the GES DISC for the dissemination of MERRA. DMM is funded by a NERC grant. Finally EV thanks the department of Geosciences of the Ecole Normale Superieure (Paris) for having given to him the opportunity to carry out such a research project.

Open Access This article is distributed under the terms of the Creative Commons Attribution License which permits any use, distribution, and reproduction in any medium, provided the original author(s) and the source are credited.

\section{References}

Andrews DG, Holton JR, Leovy CB (1987) Middle atmosphere dynamics. Academic Press, Orlando

Braesicke P, Langematz U (2000) On the occurence and evolution of extremely high temperatures at the polar winter stratopause-a gcm study. Geophys Res Lett 27(10):1467-1470

Chandran A, Collins R, Garcia R, Marsh D (2011) A case study of an elevated stratopause generated in the whole atmosphere community climate model. Geophys Res Lett 38(L08804): doi:10.1029/ 20010GL046566

Chandran A, Collins R, Garcia R, Marsh D, Harvey VL, Yue J, de la Torre L (2013) A climatology of elevated stratopause events in the whole atmosphere community climate model. J Geophys Atmos Res 118:1234-1246. doi:10.1002/jgrd.50123

Charney JG, Drazin PG (1961) Propagation of planetary-scale disturbances from the lower into the upper atmosphere. J Geophys Res 66:83-109 
Cohen J, Jones J (2012) Tropospheric precursors and stratospheric warmings. J Clim 25:1780-1790. doi:10.1175/JCLI-D-11-00701.1

Ern M, Ploeager F, Preusse P, Gille JC, Gray LJ, Kalish S, Mlynczak MG, Russell JM III, Riese M (2014) Interaction of gravity waves with the qbo: a satellite perspective. J Geophys Res 119: doi:10.1 002/2013JD020731

Fairlie TDA, Fisher M, O'Neill A (1990) The development of narrow baroclinic zones and other small-scale structure in the stratosphere during simulated majord warmings. Q J R Meteorol Soc 116:287-315

France JA, Harvey VL (2013) A climatology of the stratopause in WACCM and the zonally asymmetric elevated stratopause. J Geophys Res. doi:10.1002/jgrd.50218

France JA, Harvey VL, Randall CE, Hitchman MH, Schwartz MJ (2012) A climatology of stratopause temperature and height in the polar vortex and anticyclones. J Geophys Res 117(D06116). doi:10.1029/2011JD016893

Garcia RR, Boville BA (1994) "downward control" of the mean meridional circulation and temperature distribution of the polar winter stratosphere. J Atmos Sci 51(15):2238-2245

Gille J, Barney J, Whitney J, Dials M, Woodard D, Rudolf W, Lambert A, Mankin W (2003) The high resolution dynamics limb sounder (hirdls) experiment on aura. Proc SPIE Int Soc Opt Eng 5152:162-171. doi:10.1029/2007JD008824

Gille J, et al. (2008) High resolution dynamics limb sounder: Experiment overview, recovery, and validation of initial temperature data. J Geophys Res 113(D16S43). doi:10.1029/2007JD008824

Harvey VL, Hitchman MH (1996) A climatology of the aleutian high. J Atmos Sci 53(14):2088-3001

Hitchman MH, Gille JC, Rodgers CD, Brasseur G (1989) The separated polar winter stratopause: a gravity wave driven climatological feature. J Atmos Sci 46(3):410-422

Holt LA, Randall CE, Peck ED, Marsh DR, Smith AK, Harvey VL (2013) The influence of major sudden stratospheric warming and elevated stratopause events on the effects of energetic particle precipitation in WACCM. J Geophys Res Atm 118. doi:10.1002 /2013JD020294

Kanzawa H (1989) Warm stratopause in the antarctic winter. J Atmos Sci 46(3):435-438

Labitzke K (1974) The temperature in the upper stratosphere: differences between hemispheres. J Geophys Res 79(15):2171-2175

Labitzke K (1981) Stratospheric-mesospheric midwinter disturbances: a summary of observed characteristics. J Geophys Res 86(C10):9665-9678

Limpasuvan V, Richter JH, Orsolini YJ, Stordal F, Kvissel O (2012) The roles of planetary and gravity waves during a major stratospheric sudden warming as characterized in WACCM. J Atmos Sol-Terr Phys 78-79:84-98. doi:10.1016/j.jastp.2011.03.004

Livesey NJ et al (2011) Earth observing system (eos) microwave limb sounder (mls) version 3.3 level 2 data quality and description document. Rep JPL D-33509, Jet Propul. Lab, Pasadena, Calif.

Manney GL, Krüger K, Pawson S, Minschwaner K, Schwartz M, Daffer WH, Livesey N, Mlynczac MG, Remsberg EE, Russell J III, Waters J (2008) The evolution of the stratopause during the 2006 major warming: satellite data and assimilated meteorological analyses. J Geophys Res 113(D11115). doi:10.1029/200 7JD009097

Matsuno T (1971) A dynamical model of stratospheric warmings. J Atmos Sci 28:1479-1494. doi:10.1175/1520-0469(1971)028<1479:ADMO $\mathrm{TS}<2.0 \mathrm{CO} ; 2$

Matthewman NJ, Esler JG, Charlton AJ, Polvani LM (2009) A new look at stratospheric sudden warmings. part iii: polar vortex evolution and vertical structure. J Clim 22:1566-1585

McFarlane NA (1980) The effect of orographically excited gravity wave drag on the general circulation of the lower stratosphere and troposphere. J Atmos Sci 44:1775-1800
Mitchell DM, Charlton-Perez AJ, Gray LJ (2011) Characterizing the variability and extremes of the stratospheric polar vortices using 2d moment analysis. J Atmos Sci 68:1194-1214. doi:10.1175/20 10JAS3555.1

Mitchell DM, Anstey J, Gray LJ, Baldwin MP, Charlton-Perez AJ (2013) The influence of stratospheric vortex displacements and splits on surface climate. J Clim 26(8)

Ren S, Polarvarapu S, Beagley SR, nezlin Y, (2011) The impact of gravity wave drag on mesospheric analyses of the 2006 stratospheric major warming. J Geophys Res 116(D19116). doi:10.10 29/20011JD015943

Rienecker MM, Suarez M, Gelaro R, Todling R, Bacmeister J, Liu E, Bosilovich MG, Schubert SD, Takacs L, Kim G, Bloom S, Chen J, Collins D, Conaty A, Da Silva A, Gu W, Joiner J, Koster RD, Lucchesi R, Molod A, Owens T, Pawson S, Pegion P, Redder CR, Reichle R, Robertson FR, Ruddick AG, Sienkiewicz M, Woolen J (2011) Merra: Nasa's modern-era retrospective analysis for research and applications. J Clim 24:3624-3659. doi:10.1175/JCLI-D-00015.1

Seviour WJM, Mitchell DM, Gray LJ (2013) A practical method to identify displaced and split stratospheric polar vortex events. Geophys Res Lett 138:878-888

Shepherd TG, McLandress C (2011) A robust mechanism for strengthening of the brewer-dobson circulation in response to climate change: critical-layer control of subtropical wave breaking. J Atmos Sci 68:784-797. doi:10.1175/2010JAS3608.1

Simmons AJ (1974) Baroclinic instability at the winter stratopause. Q J R Meteorol Soc 100:531-540

Siskind DE, Eckermann SD, Coy L, McCormack JP, Randall CE (2007) On recent interannual variability of the arctic winter mesosphere: Implications for tracer descent. Geophys Res Lett 34(L09806). doi:10.1029/2007GL029293

Smith AK (1997) Stationary planetary waves in upper mesospheric winds. J Atmos Sci 54:2129-2145

Thayer P, Greer K, Harvey VL (2010) Front-like behavior in the arctic wintertime upper stratosphere and lower mesosphere. J Geophys Res 115(D00N04). doi:10.1029/2010JD014278

Tomikawa Y, Sato K, Watanabe S, Kawatani Y, Miyazaki K, Takahashi M (2008) Wintertime temperature maximum at the subtropical stratopause in a t2131256 gcm. J Geophys Res 113(D17117). doi:10.1029/2008JD009786

Tomikawa Y, Sato K, Watanabe S, Kawatani Y, Miyazaki K, Takahashi M (2012) Growth of planetary waves and the formation of en elevated stratopause after a major stratospheric sudden warming in a t2131256 gcm. J Geophys Res 117(D16101). doi:10.102 9/2011JD017243

Jea Waters (2006) The earth observing system microwave limb sounders (eos mls) on the aura satellite. IEEE Trans Geosci Remote Sens 44:1075-1092. doi:10.109/TGRS.2003.873771

Waugh DW, Randel WJ (1999) Climatology of arctic and antarctic polar vortices using elliptical diagnostics. J Atmos Sci 56:1594-1614

Wright CJ, Osprey SM, Barnett JJ, Gray LJ, Gille JC (2010) High resolution dynamics limb sounder measurements of gravity wave activity in the 2006 arctic stratosphere. J Geophys Res 115(D02105). doi:10.1029/2009JD011858

Yamashita C, England SL, Immel TJ, Chang LC (2013) Gravity wave variations during elevated stratopause events using saber observations. J Geophys Res. doi:10.1002/jrgd.50474

Zülicke C, Becker E (2013) The structure of the mesosphere during sudden stratospheric warmings in a global circulation model. J Geophys Res Atmos 118. doi:10.1002/jgrd.50219 